\title{
CEM ANOS DEPOIS DA EXPERIÊNCIA KAFKIANA DO PODER, DA LEI E DA CULPA E O INICIANTE NO DIREITO
}

\author{
Ângela Kretschmann ${ }^{1}$
}

\section{Resumo}

No presente artigo busca-se refletir acerca do poder de um texto nauseante sobre o jurista iniciante ou aquele que intenta iniciar uma carreira jurídica. $\mathrm{O}$ poder de um texto que exprime náusea, cansaço, impotência diante de um poder opressor, e culpa indubitável diante de uma acusação que é obscura, e que não se aclara. $\mathrm{O}$ que se pretende é analisar os diferentes efeitos que o texto tende a causar no leitor, a partir da experiência kafkiana do poder, da lei e da culpa.

Palavras-chave: Kafka, culpa, lei, poder

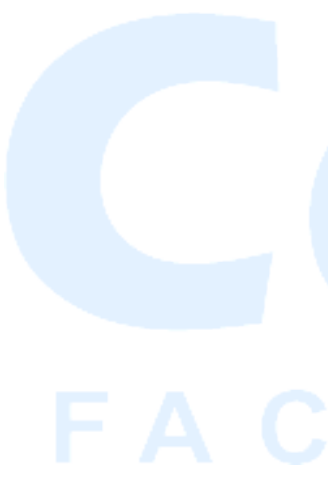

\begin{abstract}
The aim of this article is the reflextion about the power of a nauseous text from Kafka, to reflect about how the text can affect who beggin a legal career ou even who only would like to start a legal career. What one can wait from a text who expresses nausea, tiredness an impotence before an oppressive power, and undoubted guilt where there is a obscure charge, which is never cleared. The aim is to analyze the different effects that the text tends to cause on the reader from the Kafka experience of power, law and guilt.
\end{abstract}

Keywords: Kafka, law, guilty, power

\section{Introdução: a experiência kafkiana para o iniciante no Direito}

Na medida em que a leitura de "O Processo" de Franz Kafka vai se consumando, também consome o próprio leitor. Dentro do projeto Diálogos do Direito, havia a dúvida sobre se era a hora e o lugar adequados para tornar o livro o locus privilegiado de um diálogo. Afinal, o Curso de Direito ingressava em seu segundo semestre, ainda com os primeiros passos de nossos alunos. Foi uma experiência do absurdo, bem real. Uma experiência da falta de sentido, bastante dolorosa, e o temor que existia era de que caísse sobre o grupo a sensação de total falta de sentido que poderia se esparramar pelos ideais de vida de cada um que buscou no Curso de Direito a realização da liberdade.

\footnotetext{
${ }^{1}$ Professora da disciplina de Introdução ao Estudo do Direito no Cesuca, Coordenadora do Curso de Direito, Mestre em Direito (PUC/RS), Doutora em Direito (Unisinos), Pós-doutora em Direito pela Universidade de Münster, Alemanha.
} 
Com tantas possibilidades de se interpretar cada frase do livro, é de concluir-se que era desejo do autor não ver sua obra reduzida a uma única interpretação. O que em si já é bastante improvável (uma única interpretação!), ${ }^{2}$ mas de todo modo, é de fato visível a condição múltipla que a obra oferece de constituição de um rico cabedal de debates. Mais se oferecem leituras e releituras, mais se aviva o diálogo, e mais conclusões se podem tirar. Até porque, se reconhece que o Direito, com seus textos legais e jurídicos, é o lugar hermenêutico privilegiado, sempre reclamando interpretação, e aqui nem se quer chegar ao debate sobre a questão da pré-compreensão, lembrando, de todo modo, que sem pré-compreensões razoáveis nunca se chega aos problemas jurídicos (KAUFMANN \& HASSEMER, p. 190), o que de certa forma pode-se estabelecer também como problema fundamental na acusação de Josef K.

De todo modo, Kafka nos convida a compreender a lei através da literatura. Com "O Processo" intenta mostrar uma face nebulosa da lei, mas não para estabelecer sua crítica, apenas para apresentar aquilo que sente, aquilo que vê, aquilo que pressente e simplesmente deseja relatar. Essa é a lei sentida por ele, uma força desconhecida que avança de qualquer modo, uma força poderosa e desconhecida, uma força sem rosto, sem autor, sem origem, e que por mais misteriosa que possa parecer, por mais cômica que o autor às vezes a apresenta, ao mesmo tempo ela traz em si uma legitimidade sádica, que tem base na inquestionável aceitação de todos.

O livro caracteriza-se pela prisão de um sistema incompreensível, sem sentido, absurdo e que parece ser resultado da mais pura imaginação, mas que ao mesmo tempo se revela um sistema que é bem real e muito poderoso. Um sistema que de fato percebe-se existir hoje, não apenas em muitos casos concretos julgados pelo Judiciário brasileiro, mas também em qualquer setor da vida burocratizada, por isso diz-se que Kafka foi um grande visionário.

Temia-se, pois, que essa experiência do absurdo é o que poderia representar o futuro para os nossos alunos, de que modo a visão do absurdo poderia desanimá-los a continuar a caminhada. Então, outra pergunta deveria ser feita. De que modo tal visão poderia evitar a conclusão de que há uma total falta de sentido na busca da Justiça, e em tudo o que estamos fazendo?

\footnotetext{
${ }^{2}$ KAUFMANN, Arthur. A problemática da filosofia do direito ao longo da história. IN KAUFMANN, Arthur e HASSEMER, W. (Org.). Introdução à filosofia do direito e à teoria do direito contemporâneas. Gulbenkian: Lisboa, 2002. P. 190.
} 
Pois é esse o enfrentamento do presente artigo. A princípio, o que não seria compreensível aos sentidos deveria limitar-se ao que seria fruto da própria imaginação. $\mathrm{O}$ sistema que é real e ao mesmo tempo absurdo, deveria no mínimo, deprimir. Ainda mais no caso do Processo, de Kafka, onde é evidente que a luta também é insana. Mas por que é insana? E principalmente, qual o efeito que a leitura pode trazer para o leitor, especialmente o iniciantes de um Curso de direito, ou mesmo, naqueles que gostariam de ingressar no sistema? A experiência kafkiana traria um efeito necessariamente opressor, nauseante, indefinido, circular e de insegurança, ou poderia revelar seu oposto, de liberdade, clareza, definição e segurança?

\section{A experiência kafkiana do poder}

A experiência do poder, em Kafka, parece ser antes a experiência da fragilidade do indivíduo diante da supremacia de um poder totalitário. Consegue-se ter noção do sistema pelo poder que exerce sobre um personagem que não consegue reagir a ele, um sistema que lhe causa náuseas, que obscurece sua capacidade crítica, enfraquece sua capacidade de ação. Tudo é mórbido, sem vida, nauseante, diante de um poder absurdo, porque invisível. A impressão de que ele sempre chega atrasado, o que é extremamente irritante. Então, de onde vem o poder? Não seria do próprio indivíduo?

$\mathrm{Na}$ realidade, enquanto não reage ao poder opressor o personagem também deixa de exercer a liberdade. Pois a reação à opressão é um gesto em direção à liberdade, isso se não significa ela própria a liberdade. E é o que o personagem não consegue fazer, afirmar e exercer sua liberdade, autopunindo-se até a morte.

É assim que o autor atinge seu objetivo: com um personagem que pode ser visto, por um lado como um conformista, que ao fim carrega uma culpa inolvidável, o autor, de forma visionária, mostra os perigos que corre a administração da justiça e o poder da lei guardado e protegido pela cortina da burocracia. Mas o tempo todo, enquanto o personagem é morto, vítima de uma autopunição, o autor se engrandece. Pode-se dizer que vitimar o personagem e ao fim, matá-lo, foi a forma do autor compreender o que o oprime e como sobreviver a essa 
opressão. Afinal, sua luta é contra o poder do pai, assim como na obra transparece a controvérsia entre a humanidade e a máquina estatal.

O personagem é, então covardemente representado por Joseph K., o eterno culpado. Culpado por não conseguir reagir, culpado por ser fraco, por não enfrentar o poder, culpado por sua fragilidade. Com a morte do personagem, a expiação de seu crime se consome, e quem o pune é o próprio autor, Fanz Kafka. Pergunta-se, então, se com a expiação do personagem não pensava Kafka em livrar-se de sua culpa e de sua expiação...

Além disso, deve-se chamar atenção para o poder invisível que aparece em toda a obra. Ele é poderoso também porque é invisível. A acusação existe mas não se sabe quem acusa, o poder da máquina estatal é imenso, e inquestionável, como se fosse algo natural que ninguém pode questionar, a tal ponto que esparrama-se por todos os bairros e casas, ruas, bares, corredores e porões. É, portanto, como um poder natural, e daí novamente a relação entre o poder do Estado e o poder paterno, que é exercido pelo pai em relação ao filho - e do qual o filho não consegue escapar.

\section{A experiência kafkiana da lei}
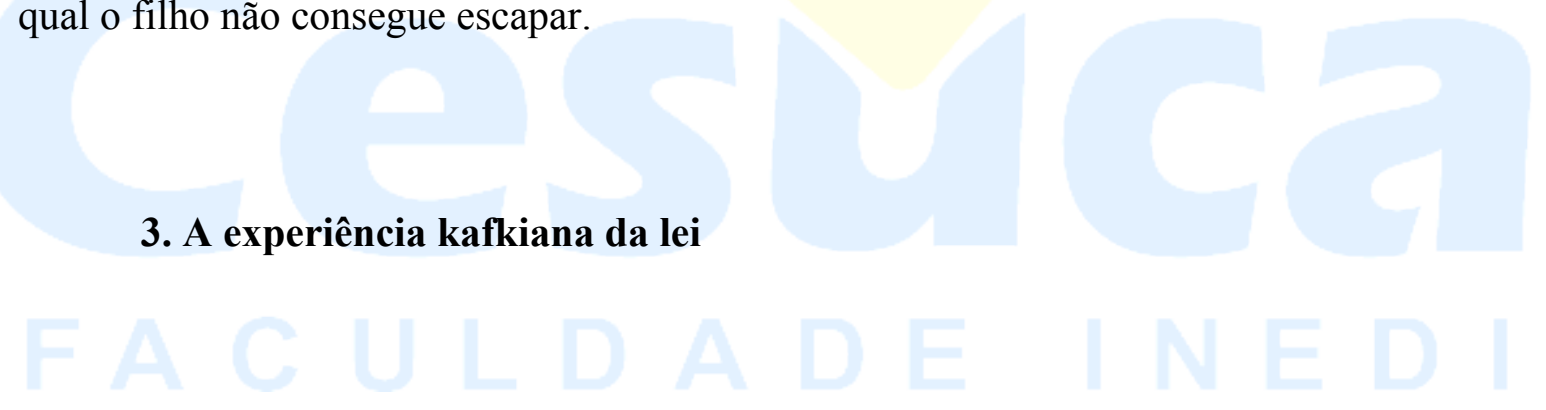

Logo no início do livro há clara advertência no sentido de que efetivamente, não obstante o absurdo, está em vigor um sistema jurídico constituído em um Estado de Direito, as leis estão efetivamente em vigor e em todo lugar impera a paz, fazendo o personagem crer que tudo pode ser uma brincadeira de um grupo de colegas do escritório.

Ora, K. vivia em um Estado de Direito, e por todos os lados imperava a paz, todas as leis seguiam vigorando; quem poderia ousar cair sobre ele dentro de sua própria moradia? $?^{3}$

Ora, o que significa Estado de Direito se não o resultado de um tumultuado fardo histórico que desembocou na era moderna com as garantias individuais e coletivas? E onde essas garantias individuais aparecem na obra? Não existem, e é por isso que o autor chama

${ }^{3}$ KAFKA, Franz. O processo. Tradução de Marcelo Backes. LP\&M: Porto Alegre, 2011. P. 17. 
atenção para a hipocrisia de um Estado de Direito que seria filho de uma época pósiluminada. E por isso Kafka ria do que escrevia. Por que de fato, se não se puder rir com as incoerências que no fundo são reais, então falta, mesmo, coragem para enfrentar o sistema que está sangrando e gemendo pela mão dos que insistem em manter os olhos fechados.

A lei constitui-se em uma realidade incompreensível, mas está vinculada nas obras do autor ao excessivo poder paterno, à própria rejeição paterna do filho que desejava ser reconhecido como escritor, e ao poder do pai opressor. O autor desejou criar o inacreditável, e assim fez o texto significante. Não há o questionamento sobre a Justiça, podendo-se concluir que na obra que a Lei e a Justiça são a mesma coisa.

O fato da lei ser inquestionável acaba mostrando a Lei como sinônimo de Justiça praticamente como algo óbvio. Nesse caso há um questionamento que é posto pela obra, pelo próprio descuidar naturalmente voluntário de qualquer vínculo entre moral e Direito, ou Justiça e Lei, pois na época era natural ver na legalidade o sinônimo de Justiça, uma vez que só após os horrores da segunda guerra mundial é que essas noções ficarão em seus lugares distintos de maneira evidente. É o que sucederá também com a ideia de Estado de Direito e democracia, que passarão a ser vistas como distintas, e em alguns casos, próximas.

O personagem chega a espantar-se com sua situação de detenção, muitas vezes esboça reações, indignações, pânicos, medo expresso em náuseas, e mesmo asco por tanto ridículo expresso pelo sistema - mas ao mesmo tempo, mantém-se inerte. Todo horror da lei sentido pelo personagem é, por outro lado, visto como algo lógico e natural da sociedade. No fundo é o autor desejando o poder de alguém que vê tudo de longe e descreve a fragilidade de um sistema e uma lei que representa o próprio poder de seu pai. Parece este ser o único modo de enfrentar o pai. Nesse caso, o autor vence, ao matar o personagem.

A relação que se faz é a de um filho que não consegue cortar o cordão umbilical e verse livre da força esmagadora do poder paterno. O filho que busca o poder do pai como um cidadão busca o poder do Estado para proteger-se, e em troca recebe uma esmagadora exploração. O filho que vê na Lei um lugar seguro, a Lei que então também representa o pai que engole o filho que se mostra inseguro demais, preso demais, ingênuo demais. 
Ao mesmo tempo, no livro o personagem vê-se preso a uma burocracia invencível, aparece como um cidadão que faz de conta que é cidadão, porque no sistema legal burocratizado não passa mais do que um objeto, estando claro que o indivíduo, pessoa, não tem a menor condição de exercer qualquer direito enquanto cidadão, livre, que vive em um Estado de Democrático de Direito. De fato, vive em um Estado de Direito, mas não democrático, mas sim, Totalitário. Por isso, tendo sido escrito antes das Grandes Guerras que ainda avassalariam o mundo, o livro também mostra os perigos de se viver em um Estado que não possui limites ao seu próprio poder, podendo sempre sujeitar o cidadão, sempre limitar sua liberdade.

\section{A experiência kafkiana da culpa}

Por outro lado, quando questiona aos agentes da detenção sobre a existência de um mandado, recebe agressivamente respostas indignadas, oprimindo o personagem que nada mais queria que exercer seu direito. Chama então, atenção, as justificativas que os agentes trazem: são funcionários de baixo escalão e mal tem condições de reconhecer um documento de identificação e só o que tem a fazer ali é servir de vigia por dez horas, mediante pagamento. O mais, que sabem, é que as altas repartições, para as quais eles trabalham, estas sim, sabem muito bem os motivos pelos quais há uma acusação e os motivos da detenção, e instruem-se com muito cuidado acerca dos motivos da detenção e da pessoa do detido (como se fosse absurdo o questionamento do detido). O mais interessante é o que vem a seguir:

Nossa repartição, pelo tanto que a conheço, e eu conheço apenas os escalões mais baixos, não se dignaria a procurar a culpa na população, mas é, conforme reza a lei, atraída pela culpa, e é obrigada a mandar vigias como nós. Isso é a lei. ${ }^{4}$

A punição vem depois da culpa, que atrai o sistema. A punição não vem depois do crime. E a culpa não está vinculada a um crime em especial, mas sim à culpa. Aqui ela está

\footnotetext{
${ }^{4}$ KAFKA, Franz. O processo. Tradução de Marcelo Backes. LP\&M: Porto Alegre, 2011. P. 20. 
vinculada à culpa. Ou seja, é a culpa que atrai o sistema que então, é obrigado a mandar vigias. De onde vem essa culpa? E como pode essa culpa ser, efetivamente, a causa da condenação? Não deveria ser o crime a causa da condenação?

É possível constatar a total ausência de ação, toda paralisia e fraqueza de enfrentar a própria lei e o sistema são ao final os responsáveis por uma culpa real, legítima, e que legitima também a punição. $\mathrm{O}$ indivíduo é punido porque não age, se omite, se esconde, se embaralha, se esquece, se perde, se atrasa, não reage, aceita. É uma culpa objetiva, ou seja, independe do sentimento de culpa do sujeito, mas sim, da sua ação, ou no caso, omissão.

No caso do personagem Joseph K., muito provavelmente, aquele sentimento de culpa implacável e indubitável o levava à busca de um castigo, mas a ausência do castigo, que pode provocar desde leves transtornos de fundo psicológico, até o suicídio, ${ }^{5}$ fazem da obra $\mathrm{O}$ Processo quase que uma tábua de salvação contra as consequências fatais de uma culpa que o persegue. Ele mesmo se culpa por não ter coragem de reagir. Sabedor que não tem culpa, mas que não consegue ir contra quem o esmaga, ele vê se então culpado de fato. Se solução, a única possibilidade que resta ao acusado é a morte. O autor acaba vendo então a morte do personagem como passo libertador. Ele é culpado por não reagir. Então o autor mata o personagem. Impõe a ele severa sanção. Pune-o exemplarmente. E com isso esperava, quem sabe, a libertação de seu pesadelo.

\section{Conclusão}

O poder muda com o tempo. $\mathrm{Na}$ teoria moderna do poder o contrato originário fundava a obrigação política, de modo que todos estavam submetidos à lei. Com a crise do poder moderno, a contratação passa a ser realizada entre grupos, forças econômicas, instituições, cada qual impondo sua força. O parlamento já não é mais a expressão máxima do poder popular, pois a realidade contemporânea é muito complexa para que o poder seja

\footnotetext{
5 "O sentimento de culpa implacável e a ausência de castigo podem provocar desde leves transtornos de fundo psicológico a, até mesmo, o suicídio” (FIORELLI, José Osmir e MANGINI, Rosana Cathya Ragazzoni. Psicologia jurídica. São Paulo: Atlas, 2011. $3^{\text {a }}$. Ed., p. 153).
} 
reduzido a representação do povo pelo parlamento. ${ }^{6}$ Imagine-se a vida de Josfef K. envolvida por associações, ONGs, agentes comunitários, e outros tantos personagens que fazem parte da vida política contemporânea. Isso apenas desperta em cada um a noção de que talvez corremos menos risco hoje do que no passado, ainda que, o risco será sempre inerente à liberdade.

E é nesse sentido que Josef K. passeia entre o desejo da lei e da segurança e o desejo de libertação. Já que a época de Josef K. reinava a confiança cega na lei, poderia ele clamar por alguma Justiça, se esta era conformada à lei, reduzida ao que era posto pelo Estado. Somente muito mais tarde virá a sugestão de que lei injusta não é absolutamente lei, o que, à época do autora, pareceria completamente irracional. Apenas com a ditadura nazista o que era irracional ficou racional, e vice-versa, de modo a que se pudesse efetivamente recorrer a essa que acabou virando uma fórmula de Radbruch, ${ }^{7}$ segundo a qual, lei que é injusta não é lei. De todo modo, não se pode pretender com isso garantir uma vitória do jusnaturalismo, ao contrário, o que importa, em qualquer situação, é evitar tanto a ditadura positivista, quanto uma ditadura de um pensamento jurídico suprapositivo, como da ideologia, que igualmente já foi utilizada para justificar a ação de Estados totalitários. ${ }^{8}$

É necessário lembrar, entretanto, que a Antiguidade deixou ao mundo moderno, como legado, um lugar privilegiado para a filosofia do direito, inclusive junto à política, mas na modernidade a ideia de Justiça será substituída pela busca do útil - em parte porque "os juristas estão sempre atrasados em relação à filosofia." 9

Ao final, a obra pode mesmo ter efeito contrário nos leitores: o leitor pode indignar-se com a total falta de sentido, com o absurdo e principalmente, com o personagem Josef K., paralisado diante da acusação. Por que uma acusação, por si só, pode gerar tamanho

\footnotetext{
${ }^{6}$ DUSO, Giuseppe. O poder além da soberania? - Tentativas contemporâneas. IN DUSO, Giuseppe (Org.). O Poder - história da filosofia política moderna. Vozes: Rio de Janeiro, p. 466.

${ }^{7}$ No seu "Quarto Minuto" de Filosofia do Direito: Mas uma coisa há que deve estar profundamente gravada na consciencia do povo e de todos os juristas: pode haver leis tais, com um tal grau de injustiça e de nocividade para o bem comum, que toda a validade e até o caráter de jurídicas não poderão jamais deixar de lhes ser negados (RADBRUCH, Gustav. Filosofia do Direito. Tradução de L. Cabral de Moncada. 6a. ed.. Coimbra: Arménio Amado, 1979. P. 415).

${ }^{8}$ KAUFMANN, Arthur. A problemática da filosofia do direito ao longo da história. IN KAUFMANN, Arthur e HASSEMER, W. (Org.). Introdução à filosofia do direito e à teoria do direito contemporâneas. Gulbenkian: Lisboa, 2002. P. 215-216.

${ }^{9}$ VILLEY, Michel. A formação do pensamento jurídico moderno. Tradução de Cláudia Berliner. São Paulo: Martins Fontes, 2005. P. 534.
} 
sentimento de culpa e levá-lo até mesmo a começar a duvidar de si mesmo, sugerindo que precisaria fazer um inventário de sua vida para averiguar cada detalhe que pudesse lhe ter escapado, ${ }^{10}$ a fim de livrar-se de fato da acusação. Entretanto, paradoxalmente o leitor de "O Processo" pode ver-se num mundo paralelo, nem tão dentro, nem tão fora do sistema que Kafka descreve, considerando a avassaladora crise do judiciário que nos atormenta.

O leitor termina o livro e pode sentir-se fora daquele sistema descrito, justamente porque boa parte da imobilidade retratada no livro decorre da própria incapacidade do personagem de mover-se, e pior, a incapacidade crítica do sistema, a incapacidade de negar uma culpa que insiste em carregar sem sequer saber o motivo. Ao terminar a leitura o leitor pode perceber-se fora do sistema (descrito no livro), amparado por um sistema com mais e múltiplos atores, com grupos comunitários, com ONGs, com associações de bairro, com novas teorias críticas do direito que estão tendo por hábito questionar o que antes era inquestionável. Colocar em dúvida o poder da lei, sugerindo sempre que necessário, uma nova compreensão do sentido da própria lei.

O livro permanece como uma sobra útil para lembrar de uma possibilidade sempre presente na vida humana. Permanece ainda como um convite permanente para a reflexão jurídica, revelando os perigos de uma acomodação na vida do jurista. E sugere, ainda, que haverá culpa em face de uma acomodação. Culpa e autopunição.

Quem sabe assim, apesar da realidade das dificuldades da Justiça de fato tentar nos engolir, como aconteceu com o personagem, de algum modo é possível sentir o imprevisível, a libertação, a potência, a oportunidade e a diferença - o alívio e o desejo de impedir que a descrição de opressão possa tornar-se de fato uma realidade, ou ao menos, se já for realidade, que o personagem, amparado pelas conquistas decorrentes dos direitos garantidos em cartas de direitos humanos e fundamentais, possam garantir também a capacidade de reação contra o sistema. O livro, assim, quase 100 anos após ter sido escrito, pode ser visto como um convite à reação, um convite à ação, um convite ao pensar crítico, sempre poderoso porque transformador.

10 ..."era preciso restabelecer na memória toda a sua vida anterior em seus mínimos atos e acontecimentos, expondo-a e examinando-a sob todos os aspectos” (KAFKA, Franz. O processo. Tradução de Marcelo Backes. LP\&M: Porto Alegre, 2011. P. 152). 


\section{REFERÊNCIAS BIBLIOGRÁFICAS}

DUSO, Giuseppe (Org.). O Poder - história da filosofia política moderna. Vozes: Rio de Janeiro, 2005.

FIORELLI, José Osmir e MANGINI, Rosana Cathya Ragazzoni. Psicologia jurídica. São Paulo: Atlas, 2011. $3^{\mathrm{a}}$. Ed.

KAFKA, Franz. O processo. Tradução de Marcelo Backes. LP\&M: Porto Alegre, 2011.

KAUFMANN, Arthur e HASSEMER, W. (Org.). Introdução à filosofia do direito e à teoria do direito contemporâneas. Gulbenkian: Lisboa, 2002

RADBRUCH, Gustav. Filosofia do Direito. Tradução de L. Cabral de Moncada. 6a. ed.. Coimbra: Arménio Amado, 1979.

VILLEY, Michel. A formação do pensamento jurídico moderno. Tradução de Cláudia Berliner. São Paulo: Martins Fontes, 2005. P. 534. 